\title{
$\mathrm{HEVC}$ 의 $\mathrm{GPB}$ 슬라이스에서 양예측 모드의 동일 움직임 정보에 대한 성능 향상 방안
}

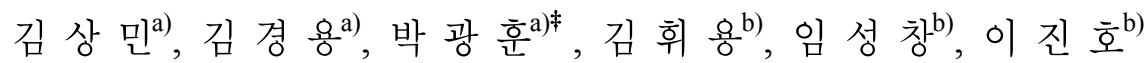

\section{Coding Efficiency Improvement for Identical Motion Information of Bi-prediction Mode within the GPB Slcice of HEVC}

\author{
Sang Min Kim ${ }^{\text {a) }}$, Kyung Yong Kimª, Gwang Hoon Park ${ }^{\text {a) }}$, Hui Yong Kim ${ }^{\text {b) }}$, \\ Sung Chang Lim $^{\text {b) }}$, and Jin Ho Lee ${ }^{\text {b) }}$
}

요 약

본 논문에서는 현재 표준화가 진행 중인 HEVC(High Efficiency Video Coding)에서 양예측(bi-predictive)모드에 존재하는 문제점을 거론하고 문제점에 대한 해결방안을 제시하여 부호화 효율을 증가시키고 계산 복잡도를 감소시키는 방법을 제안한다. 현재 HM 3.0 에 서는 양예측을 사용하는 블록에서 L0 움직임 정보와 L1 움직임 정보가 동일해지는 경우가 빈번히 발생한다. 본 논문에서는 이러한 현 상이 발생하는 경우 L1의 움직임 벡터를 현재 블록의 주변 블록의 $(0,0)$ 이 아닌 L0 움직임 벡터로 대체 하고, 여전히 L0 움직임 벡터 와 L1 움직임 벡터가 동일할 경우 예측모드를 단예측으로 변경하여 부호화 성능을 향상 시키고 계산 복잡도를 감소시키는 방법을 제 안하였다. 실험 결과, $\mathrm{LD}$ (Low-Delay) 실험조건의 경우 기존 대비 복호화기의 수행시간을 $2 \% \sim 5 \%$ 감소시키고 부호화 성능을 약 $0.3 \% \sim 0.5 \%$ 향상 시켰다.

\begin{abstract}
This paper proposes the method which reduces complexity and improves coding efficiency by solving a problem of HEVC bi-prediction. In current HM 3.0, it is frequently occurred that L0 motion information and L1 motion information are identical in blocks which are bi-predicted. In this case, L1 motion vector is replaced by non-zero motion vector which belongs to first available neighbor block of current block. If they are still identical, prediction mode is replaced by uni-prediction. As an experimental result, in $\mathrm{LD}$ (Low-Delay) case, decoding time is reduced roughly $2 \% \sim 5 \%$ and coding gain is roughly $0.3 \% \sim 0.5 \%$ compared with the HM 3.0 anchor.
\end{abstract}

Keyword: HEVC(High Efficiency Video Coding), Bi-prediction, Merge

a) 경희대학교 전자정보대학 컴퓨터공학과

Media Lab., College of Electronics and Information, Kyung Hee University

b) 한국전자통신연구원

ETRI

\# 교신저자 : 박광훈(ghpark@khu.ac.kr)

※ 본 연구는 방송통신위원회의 ETRI 연구지원 사업[KCA-2011-(11921-02001), 무안경 다시점 3D지원 UHDTV 방송 기술개발]과 지식경제부 및 정보통 신산업진흥원의 대학 IT연구센터 지원사업(NIPA-2011-(C1090-1111-0001))의 연구결과로 수행되었음.

· 접수일(2011년10월10일),수정일(2011년11월16일),게재확정일(2011년11월16일) 


\section{I. 서 론}

고화질, 고해상도 컨텐츠의 엄청난 데이터량을 처리하기 위해서 기존 H.264/AVC ${ }^{[1]}$ 를 대체할 새로운 동영상 부호화 표준의 필요성이 대두 되었다. 이러한 요구에 부합하기 위 하여 ISO/IEC JTC1/SC29/WG11 MPEG과 ITU-T SG16 Q6 VCEG은 H.264/AVC 기술표준 대비 2배 정도의 압축 효율을 목표로 한 차세대 동영상 부호화 기술인 $\mathrm{HEVC}$ (High Efficiency Video Coding) ${ }^{[2]}$ 의 표준화를 진행하고 있다. $\mathrm{HEVC}$ 에서는 화면 간 예측 시 단예측을 사용하여 부호 화된 슬라이스를 P 슬라이스, 양예측을 사용하여 부호화된 슬라이스를 B 슬라이스라 한다. 양예측을 사용할 경우 해 당 블록은 최대 두 개의 움직임 정보(움직임 벡터, 참조 픽 쳐 번호)를 가질 수 있다. 참조 픽쳐는 참조픽쳐 리스트에 의해 관리 되며, 일반적으로 순방향 참조 픽쳐(과거영상)는 리스트0(list $0 ; \mathrm{L} 0)$ 에, 역방향 참조 픽쳐(미래영상)는 리스 트1(list $1 ; \mathrm{L} 1$ )에 할당된다.

$\mathrm{HEVC}$ 의 저지연(Lowdelay)환경에서는 화면 간 예측 효 율을 높이기 위해 P 슬라이스 대신 GPB(Generalized P and $B)^{[3]}$ 슬라이스를 사용한다. GPB 슬라이스는 일반적인 B 슬 라이스와 마찬가지로 하나의 블록 당 최대 2 개의 움직임 정 보를 가질 수 있다. 하지만 L0 참조 픽쳐 리스트와 L1 참조 픽쳐 리스트는 항상 동일해야 하며, 참조 픽쳐 리스트에 저 장되는 영상들은 현재 영상보다 시간적으로 과거 영상으로 만 이루어져야한다. 본 논문에서는 GPB 슬라이스처럼 순방 향 예측만이 가능한 B 슬라이스를 순방향 B 슬라이스(forward B slice)라 정의 한다. 이러한 순방향 B 슬라이스에서 $\mathrm{L} 0$ 움직임 정보와 $\mathrm{L} 1$ 움직임 정보가 동일하게 되는 경우가 주로 발생하고, 그 결과 똑같은 움직임 보상 과정을 불필요 하게 반복하여 수행하는 결과를 야기 시킨다. 따라서 본 논 문에서는 이러한 문제에 대한 원인을 분석하고 이를 해결하 여 계산 복잡도를 감소시키기 위한 방안을 제시한다.

본 논문의 구성은 다음과 같다. II장에서는 기존 양예측 의 문제점에 대하여 설명하고, III장에서는 문제점을 해결 하기 위한 방법을 제안한다. IV장에서는 제안하는 방법의 성능을 측정하고, 마지막으로 $\mathrm{V}$ 장에서 결론을 기술한다.

\section{II. 기존 양예측의 문제점}

[그림 1]은 표준화가 진행 중인 $\mathrm{HEVC}$ 의 참조 모델 $\mathrm{HM} 3.0^{[2]}$ 을 이용해서 저지연 환경으로 부호화한 영상이다. 저지연 환경으로 부호화를 수행할 경우, 단예측과 양예측 이 모두 사용되며, 양예측의 경우 순방향 양예측을 이용하 여 부호화되기 때문에 각 PU(Prediction Unit) ${ }^{[2]}$ 마다 최대 두 개의 움직임 정보가 존재할 수 있다. [그림 1]에서 " $1|-24,-23| 0,0$ "는 각각 " $\mathrm{POC}$ |움직임벡터|움직임벡터의 차 이"를 나타내며, 위쪽은 L0 움직임 정보를 나타내고 아래 쪽은 L1 움직임 정보를 나타낸다. 그리고 "n.a"는 움직임 정보가 없음을 의미한다. $\mathrm{Merge}^{[2]}$ 모드로 부호화 되었을 경 우 "Merge : merge Index"가, AMVP ${ }^{[2]}$ 모드 부호화 되었을 경우 "AMVP : | L0 참조픽쳐번호, L1 참조픽쳐번회|" 가 표시된다. [그림 1]을 보면, $\mathrm{L} 0$ 움직임 정보와 $\mathrm{L} 1$ 움직임 정 보가 동일한 블록이 다수 존재한다는 것을 알 수 있다. L0 움직임 정보와 $\mathrm{L} 1$ 움직임 정보가 동일하다는 의미는 $\mathrm{L} 0$ 의 움직임 벡터와 $\mathrm{L} 1$ 의 움직임 벡터가 같고 동일한 $\mathrm{POC}($ Picture Order Count)의 영상을 참조영상으로 사용한 다는 것이다.

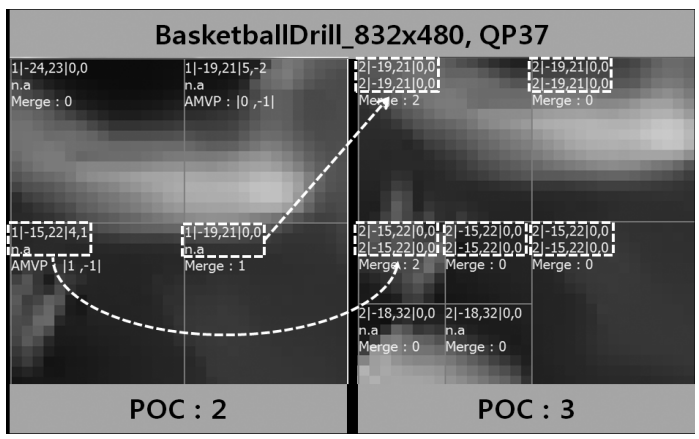

그림 1. 부호화된 영상의 움직임 정보

Fig 1. Motion information of encoded picture

[표 1]은 $\mathrm{HEVC}$ 공통실험조건 ${ }^{[4]}$ 에서 사용하는 실험 영상 을 이용하여 순방향 B 슬라이스에서 L0 움직임 정보와 L1 움직임 정보가 같아지는 블록의 비율을 $\mathrm{QP}(\mathrm{Quantization}$ Parameter)별로 나타낸 표이다.

[표 1]에서 $\mathrm{LDHE}, \mathrm{LDLC}$ 의 실험 조건의 경우 $\mathrm{L} 0$ 움직임 
정보와 $\mathrm{L} 1$ 움직임 정보가 동일한 경우가 전체의 약 $30 \%$ 를 차지한다. 이러한 동일 움직임 정보는 merge/skip 부호화 모드 ${ }^{[2]}$ 에서 시간적 움직임 벡터를 결정하는 과정에서 발생 된다. [그림 1]의 표시된 부분과 같이, 참조 영상에서 현재 블록과 대응하는 블록에 L0 움직임 정보가 존재하고 $\mathrm{L} 1$ 움 직임 정보가 존재하지 않으면, 현재 블록의 시간적 움직임 벡터의 $\mathrm{L} 0$ 움직임 정보와 $\mathrm{L} 1$ 움직임 정보 모두 참조 영상 에서 현재 블록과 대응하는 블록의 L0 움직임 정보로 설정 된다. 이는 merge/skip 부호화모드에 의해서 공간적으로 확 산된다. 이러한 L0 움직임 정보과 L1 움직임 정보의 동일 성은 움직임 보상 단계의 중복으로 인한 계산 복잡도의 증 가를 유발한다.

표 1. 순방향 B 슬라이스에서 L0 움직임 정보와 L1움직임 정보가 같아지는 블록의 비율

Table 1. Ratio of blocks which have identical motion informations in forward B slice

\begin{tabular}{|l|c|c|c|}
\hline & QP & LD HE(\%) & LD LC(\%) \\
\hline \multirow{4}{*}{ Class A } & 37 & & \\
\cline { 2 - 4 } & 32 & & \\
\cline { 2 - 4 } & 27 & & \\
\cline { 2 - 4 } & 22 & & \\
\hline \multirow{4}{*}{ Class B } & 37 & $38.3 \%$ & $38.6 \%$ \\
\cline { 2 - 4 } & 32 & $28.8 \%$ & $28.4 \%$ \\
\cline { 2 - 4 } & 27 & $21.0 \%$ & $19.8 \%$ \\
\cline { 2 - 4 } & 22 & $11.6 \%$ & $9.2 \%$ \\
\hline \multirow{4}{*}{ Class C } & 37 & $31.3 \%$ & $33.6 \%$ \\
\cline { 2 - 4 } & 32 & $21.0 \%$ & $23.2 \%$ \\
\cline { 2 - 4 } & 27 & $14.2 \%$ & $16.2 \%$ \\
\cline { 2 - 4 } & 22 & $9.3 \%$ & $10.1 \%$ \\
\hline \multirow{5}{*}{ Class D } & 37 & $32.9 \%$ & $35.0 \%$ \\
\cline { 2 - 4 } & 32 & $22.6 \%$ & $23.7 \%$ \\
\cline { 2 - 4 } & 27 & $15.4 \%$ & $16.3 \%$ \\
\cline { 2 - 4 } & 22 & $10.0 \%$ & $10.2 \%$ \\
\hline \multirow{5}{*}{ Class E } & 37 & $71.0 \%$ & $70.2 \%$ \\
\cline { 2 - 4 } & 32 & $55.1 \%$ & $57.7 \%$ \\
\cline { 2 - 4 } & 27 & $41.0 \%$ & $34.8 \%$ \\
\cline { 2 - 4 } & 22 & $29.6 \%$ & $29.4 \%$ \\
\hline Average & & $28.3 \%$ & \\
\hline
\end{tabular}

\section{III. 문제점을 해결하기 위해 제안하는 방법}

본 논문에서는 II장에서 밝힌 문제점을 해결하기 위해서 다음과 같은 세 가지 방법을 제시한다.
1) L0 움직임 정보와 L1 움직임 정보가 동일하면, 단 예측으로 변경하는 방법

2) 중복된 L1 움직임 벡터를 주변 블록의 움직임 벡터 로 대체하는 방법

3) 중복된 L1 움직임 벡터를 주변 블록의 움직임 벡터 로 대체하고, 그 이후에도 L0 움직임 정보와 L1 움 직임 정보가 동일하면 단예측으로 변경하는 방법

1) 첫 번째 방법은 merge/skip 부호화 모드의 시간적 움 직임 정보를 결정할 때 $\mathrm{L} 0$ 움직임 정보와 $\mathrm{L} 1$ 움직임 정보 를 유추한 후 동일 움직임 정보 여부를 판단하여 동일한 움직임 정보일 경우, 해당 블록의 움직임 정보 예측 모드를 양예측에서 단예측으로 변경하는 방법이다.

2) 두 번째 방법은 L0 움직임 정보와 L1움직임 정보가 동일할 경우, 현재 블록의 주변블록 중 $\mathrm{L} 0$ 움직임 벡터가 $(0,0)$ 이 아닌 블록을 [그림 2]의 $\mathrm{A}$ (왼쪽), $\mathrm{B}$ (위쪽), $\mathrm{E}$ (왼쪽 위)의 순서대로 탐색하여 가장 먼저 찾아지는 블록의 L0 움직임 벡터를 현재 블록의 L1 움직임 벡터로 사용한다.

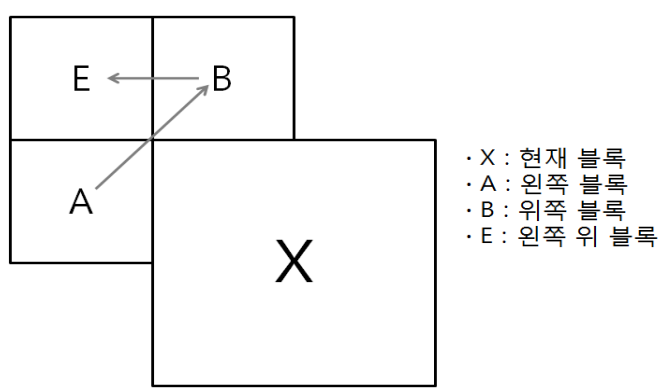

그림 2. 주변 블록의 탐색 순서

Fig 2. Search order of neighbor blocks

3) 세 번째 방법은 첫 번째 방법과 두 번째 방법을 함께 수행하는 방법이다. L0 움직임 정보와 L1 움직임 정보의 동일성 여부를 판단하고, 동일한 움직임 정보일 경우 주변 블록에서 $(0,0)$ 이 아닌 움직임 벡터를 가지고 있는 블록을 찾아 그 블록의 $\mathrm{L} 0$ 움직임 벡터를 현재 블록의 $\mathrm{L} 1$ 움직임 벡터로 사용한다. 그 후 $\mathrm{L} 0$ 움직임 정보와 $\mathrm{L} 1$ 움직임 정보 의 동일성 여부를 다시 한번 판단하여 여전히 동일할 경우 예측 모드를 양예측에서 단예측으로 변경한다. 


\section{IV. 제안하는 방법의 성능 평가}

본 논문에서 제안하는 방법의 우수성을 검증하기 위해

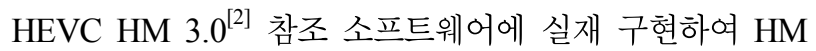
3.0 과의 비교 실험을 수행하였다. 실험 영상 및 조건은 $\mathrm{HEVC}$ 의 공통실험조건 ${ }^{[4]}$ 을 준수하였다. 제안하는 방법의 계산 복잡도를 측정하기 위해 실험 영상을 인코더로 부호 화하여 비트스트림을 생성하는 과정의 평균시간과 비트스 트림을 복호화 하는 과정의 평균시간을 측정하였다. 또한 부호화 효율을 측정하기 위해 평균적인 bit-rate 감소량을 나타내는 BD-Bitrate 방법 ${ }^{[5]}$ 을 사용하였다.

표 2. 첫 번째 방법의 실험 결과

Table 2. Experimental result of 1 st method

\begin{tabular}{|c|c|c|c|c|c|c|}
\hline & \multicolumn{3}{|c|}{ Low delay $\mathrm{B} \mathrm{HE}$} & \multicolumn{3}{|c|}{ Low delay B LC } \\
\hline & $\mathrm{Y}$ & $\mathrm{U}$ & $\mathrm{V}$ & $\mathrm{Y}$ & $\mathrm{U}$ & $\mathrm{V}$ \\
\hline \multicolumn{7}{|l|}{ Class A } \\
\hline Class B & -0.1 & 0.2 & 0.0 & 0.0 & -0.1 & -0.3 \\
\hline Class C & 0.0 & 0.1 & 0.0 & 0.0 & -0.1 & -0.1 \\
\hline Class D & 0.0 & 0.1 & 0.3 & 0.0 & -0.3 & -0.3 \\
\hline Class $\mathrm{E}$ & 0.0 & 0.3 & -0.2 & 0.0 & 0.0 & -0.6 \\
\hline Overall & 0.0 & 0.2 & 0.0 & 0.0 & -0.1 & -0.3 \\
\hline Enc Time[\%] & \multirow{2}{*}{\multicolumn{3}{|c|}{$\begin{array}{c}100 \% \\
96 \%\end{array}$}} & \multirow{2}{*}{\multicolumn{3}{|c|}{$\begin{array}{c}100 \% \\
96 \%\end{array}$}} \\
\hline Dec Time[\%] & & & & & & \\
\hline
\end{tabular}

표 3. 두 번째 방법의 실험 결과

Table 3. Experimental result of 2nd method

\begin{tabular}{|c|c|c|c|c|c|c|}
\hline & \multicolumn{3}{|c|}{ Low delay B HE } & \multicolumn{3}{|c|}{ Low delay B LC } \\
\hline & $\mathrm{Y}$ & $\vec{U}$ & $\mathrm{~V}$ & $\mathrm{Y}$ & $\mathrm{U}$ & $\mathrm{V}$ \\
\hline \multicolumn{7}{|l|}{ Class A } \\
\hline Class B & -0.3 & -0.5 & -0.7 & -0.6 & -1.0 & -1.2 \\
\hline Class C & -0.3 & -0.6 & -0.6 & -0.3 & -0.6 & -0.6 \\
\hline Class D & -0.1 & -0.1 & -0.1 & -0.2 & -0.2 & -0.3 \\
\hline Class $\mathrm{E}$ & -0.2 & -0.7 & -0.9 & -0.6 & -1.1 & -1.6 \\
\hline Overall & -0.2 & -0.5 & -0.5 & -0.4 & -0.7 & -0.9 \\
\hline Enc Time[\%] & \multicolumn{3}{|c|}{$100 \%$} & \multicolumn{3}{|c|}{$100 \%$} \\
\hline Dec Time[\%] & \multicolumn{3}{|c|}{$94 \%$} & \multicolumn{3}{|c|}{$95 \%$} \\
\hline
\end{tabular}

표 4. 세 번째 방법의 실험 결과

Table 4. Experimental result of 3rd method

\begin{tabular}{|c|c|c|c|c|c|c|}
\hline & \multicolumn{3}{|c|}{ Low delay $\mathrm{B} \mathrm{HE}$} & \multicolumn{3}{|c|}{ Low delay B LC } \\
\hline & $\bar{Y}$ & $\vec{U}$ & $\mathrm{v}$ & $\mathrm{Y}$ & $\mathrm{U}$ & $\mathrm{V}$ \\
\hline \multicolumn{7}{|l|}{ Class A } \\
\hline Class B & -0.3 & -0.4 & -0.4 & -0.7 & -0.9 & -1.0 \\
\hline Class C & -0.3 & -0.6 & -0.7 & -0.4 & -0.6 & -0.8 \\
\hline Class D & -0.2 & -0.3 & -0.1 & -0.2 & -0.7 & 0.0 \\
\hline Class $\mathrm{E}$ & -0.3 & -0.9 & -1.1 & -0.7 & -1.8 & -1.5 \\
\hline Overall & -0.3 & -0.5 & -0.5 & -0.5 & -0.9 & -0.8 \\
\hline Enc Time[\%] & \multicolumn{3}{|c|}{$101 \%$} & \multicolumn{3}{|c|}{$101 \%$} \\
\hline Dec Time[\%] & \multicolumn{3}{|c|}{$95 \%$} & \multicolumn{3}{|c|}{$98 \%$} \\
\hline
\end{tabular}

[표 2], [표 3], [표 4]는 각각 첫 번째, 두 번째, 세 번째 해결방법의 부호화/복호화 시간과 BD-Bitrate를 나타낸 것이 다. 첫 번째 방법에서는 복호화 시간이 감소하였고, 두 번째 방법에서는 부호화 효율이 개선된 것을 알 수 있다. 첫 번째 방법과 두 번째 방법이 함께 사용된 세 번째 방법에서는 복호
화 시간과 부호화 효율이 모두 개선된 것을 알 수 있다.

LDHE 조건에서는 복호화기의 수행시간을 $4 \% 6 \%$ 감소 시키고 부호화 성능을 약 $0.0 \% \sim 0.3 \%$ 향상 시켰으며, LDLC 조건에서는 복호화기의 수행 시간을 $2 \%-5 \%$ 감소 시켰고 부호화 성능을 약 $0 \% \sim 0.5 \%$ 향상시켰다. 특히 L1 움직임 정보를 주변 블록의 움직임 벡터로 대체하고 여전 히 동일한 움직임 정보일 경우 단예측으로 변경하는 세 번 째 해결 방법의 경우, LDHE 조건에서는 복호화기의 수행 시간을 $5 \%$ 감소시키고 부호화 성능을 약 $0.3 \%$ 향상 시켰 으며, LDLC 조건에서는 복호화기의 수행 시간을 $2 \%$ 감소 시켰고 부호화 성능을 약 $0.5 \%$ 향상시켰다.

\section{V. 결 론}

$\mathrm{HEVC}$ 에서 양예측을 수행할 때 L0 움직임 정보와 L1 움 직임 정보가 동일해지는 블록이 다수 발생한다. 이는 똑같 은 움직임 보상 과정을 불필요하게 두 번 반복함으로써 계 산 복잡도의 증가를 야기시킨다. 따라서 본 논문에서는 이 러한 문제를 해결하기 하기 위한 방안으로 양예측을 단예 측으로 변경하거나 L1 움직임 벡터를 주변의 인접한 블록 의 움직임 벡터로 변경하는 방법을 제안하였다. 그 결과 L0 움직임 정보와 $\mathrm{L} 1$ 움직임 정보의 동일성을 제거할 수 있었 으며, HM 3.0대비 복호화기의 수행시간을 $2 \% \sim 5 \%$ 감소 시키고 부호화 성능을 약 $0.3 \% \sim 0.5 \%$ 향상 시켰다.

\section{참 고 문 헌}

[1] ITU-T Recommendation H.264 and ISO/IEC 14496-10 (MPEG-4 Part 10 AVC), "Advanced Video Coding for Generic Audiovisual Services," Version 1: March 2003, Version 2: May 2004, Version 3: March 2005, Version 4: September 2005, Version 5 and Version 6: June 2006, Version 7: April 2007, Version 8: July 2007.

[2] Joint Collaborative Team on Video Coding (JCT-VC) of ITU-T SG16 WP3 and ISO/IEC JTC1/SC29/WG11, "WD3: Working Draft 3 of High-Efficiency Video Coding”, JCTVC-E603, Geneva, Switzerland, March 2011.

[3] Joint Collaborative Team on Video Coding (JCT-VC) of ITU-T SG16 WP3 and ISO/IEC JTC1/SC29/WG11, "HM3: High-Efficiency Video Coding(HEVC) Test Model3 Encoder Description”, JCTVC-E603, Geneva, Switzerland, March 2011.

[4] Joint Collaborative Team on Video Coding (JCT-VC) of ITU-T SG16 WP3 and ISO/IEC JTC1/SC29/WG11, "Common test conditions and software reference configurations", JCTVC-E700, Geneva, Switzerland, March 2011.

[5] G. Bjøntegaard, "Calculation of average PSNR differences between RD-curves," ITU-T SG16 Q.6, VCEG-M33, Texas, USA, April 2001. 